\title{
Valorización social del patrimonio arqueológico para un desarrollo turístico de la provincia de Petorca
}

\section{Social valorization of archaeological heritage for a tourist development in the province of Petorca}

\author{
Alan Muñoz ${ }^{1}$, Felipe Araneda ${ }^{2}$, María Soledad Ostria $^{3}$
}

\footnotetext{
${ }^{1}$ Universidad de Valparaíso. Facultad de Arquitectura. Escuela de Gestión en turismo y cultura. Av. El Parque \#570 Valparaíso,

$\otimes$ Chile. alan.munoz@uv.cl

(B) https://orcid.org/0000-0001-7103-9250

${ }^{2}$ Universidad de Valparaíso. Facultad de Arquitectura. Escuela de Gestión en turismo y cultura. Av. El Parque \#570 Valparaíso, Chile.

$凶$ fe.araneda@gmail.com 2. https://orcid.org/0000-0002-6393-9563

${ }^{3}$ Universidad de Valparaíso. Facultad de Arquitectura. Escuela de Gestión en turismo y cultura. Av. El Parque \#570 Valparaíso, Chile.

凶soledad.ostria@uv.cl

b https://orcid.org/0000-0002-7963-2785
}

*Autor de correspondencia: alan.munoz@uv.cl

\section{SIEMBRA}

https://revistadigital.uce.edu.ec/index.php/SIEMBRA ISSN-e: $2477-8850$

ISSN: $1390-8928$

Periodicidad: semestral

vol. 8, núm. 2, 2021

siembra.fag@uce.edu.ec

DOI: https://doi.org/10.29166/siembra.v8i2.3365

Esta obra está bajo una licencia internacional Creative Commons Atribución-NoComercia

\section{Resumen}

El objetivo de este estudio apunta a identificar aspectos relevantes para la construcción de un modelo de desarrollo turístico en la provincia de Petorca, para lo cual se analizaron los bienes arqueológicos existentes en el territorio, la valorización social de los mismos por parte de la comunidad, y el grado de adecuación de dichos bienes para ser utilizados en la actividad turística. Además, se hizo una revisión de teorías y literatura asociadas a estas áreas, lo que permitió generar una base de conocimiento para discutir acerca del desarrollo del territorio considerando los resultados obtenidos. El trabajo se fundamentó en una metodología de enfoque mixto, con técnicas de campo y entrevistas a actores locales. Como resultado se obtuvo una alta valorización de los habitantes acerca de su patrimonio arqueológico, pero un nivel de adecuación inicial para uso turístico de estos mismos bienes, lo que permite plantear algunas orientaciones para la construcción de un modelo de desarrollo turístico basado en el patrimonio arqueológico.

Palabras clave: territorio, patrimonio arqueológico, desarrollo local, turismo, valorización social.

\begin{abstract}
This study aims to identify relevant aspects for the construction of a tourism development model in the province of Petorca. The archaeological assets in the territory, its social valorization by the community and its suitability degree for tourism use were analyzed. In addition, a review of theories and literature associated with these areas was made, which provides a knowledge base to discuss the development of the territory based on the results obtained. The work was based on a mixed approach methodology, with field techniques and interviews to local actors. As result, the inhabitants' valorization of their archaeological heritage was high, but their initial level of suitability for tourism use of these same assets was low, which allows us to propose some guidelines for the construction of a tourism development model based on archaeological heritage.
\end{abstract}

Keywords: territory, archaeological heritage, local development, tourism, social valorization 
La provincia de Petorca, es una de las ocho provincias que componen la Región de Valparaíso, siendo la más septentrional y, a su vez, la más extensa territorialmente, con una superficie total de $4.589 \mathrm{~km}^{2}$. Dentro de su administración, la provincia está compuesta por las comunas de: Cabildo, Papudo, Petorca, Zapallar y La Ligua, siendo esta última la capital provincial. La población total del territorio asciende a 78.299 habitantes, de los cuales el $67 \%$ de ellos corresponde a población urbana, mientras que el $33 \%$ restante pertenece a población rural.

Este territorio comprende una realidad compleja, asociada a problemáticas como la escasez hídrica, que se ha acrecentado desde hace más de una década, sumado al desarrollo de actividades productivas y económicas que no han favorecido las condiciones de vida esperadas, como son la minería y el sector inmobiliario. El territorio es posible dividirlo en tres subzonas, las cuales por condición geográfica quedan clasificadas como zona costera: Papudo y Zapallar; zona intermedia: La Ligua, y zona interior: Cabildo y Petorca. Esta subcategorización permite vislumbrar características compartidas entre las comunas en cuestión. En el caso del sector costero de la provincia, se destacan históricamente como balnearios tradicionales y reconocidos en todo el país, ligados en cierta medida a sectores exclusivos de la sociedad en general. Sin embargo, en la actualidad esa faceta peculiar ha ido mutando, sobre todo en la comuna de Papudo, no así en Zapallar, donde se destaca la segunda residencia de personas de un segmento alto a nivel socioeconómico. Por otra parte, en el sector interior del territorio, históricamente el desarrollo tanto agrícola y especialmente minero de ambas comunas ha forjado una identidad rural de lucha y esfuerzo por parte de las comunidades que habitan estos territorios. Más, en la actualidad, estas dos comunas se han visto en la palestra como zonas símbolo ante la crisis hídrica que se presenta en el país, junto también a problemas ambientales ligados a la minería y a los residuos con que la industria agobia a la comunidad (relaves). Otro punto en común en el tema agrícola es, sin duda, la presencia de monocultivos dentro de los límites comunales, lo que impacta ambientalmente. Por último, la comuna de La Ligua, como zona intermedia del territorio, juega un rol articulador y primordial dentro de la provincia al tratarse, como se mencionó anteriormente, de la comuna capital provincial. Este rol "administrativo" le otorga un carácter asociador de todo el territorio provincial, estableciéndose como el suelo común dentro de la provincia donde se aglutinan la mayoría de las personas de esta comunidad.

Los bienes y sitios arqueológicos existentes en la provincia constituyen un patrimonio local poco utilizado y con escasa vinculación con las actividades relacionadas al turismo. Desde esta perspectiva, pero considerando además la realidad compleja del territorio, se plantea la necesidad de indagar en la búsqueda de un modelo para el desarrollo turístico local, que parta de la existencia de recursos atractivos propios, y que podrían permitir el desarrollo de actividades productivas complementarias para el desarrollo local. En este sentido, el objetivo principal del trabajo realizado es identificar la valorización social de dicho patrimonio, a la vez que analizar el grado de adecuación que tiene para su uso desde el turismo. Con base en la literatura y las observaciones que se han dado al respecto, se discuten algunas perspectivas que orienten el desarrollo futuro del turismo en la búsqueda de un modelo propio para las condiciones que el territorio presenta.

\section{Revisión de la literatura}

\subsection{Desarrollo local y patrimonio arqueológico}

El desarrollo territorial ha sido analizado en diversos estudios y son muchos los autores que han discutido al respecto, sin embargo, no todos hacen hincapié en la importancia que puede tener la incorporación de los habitantes (Álvarez García y Rendón Acevedo, 2010) como actores sociales y también productivos. La forma en que los distintos espacios geográficos pueden desarrollarse responde a cuestiones políticas, industriales, económicas, entre otras; sin embargo, el rol que pueden tener los mismos actores locales dependerá de la manera en que se proyecte dicho desarrollo. En este sentido, la construcción del desarrollo desde abajo, desde lo local, permite la valorización entre los mismos habitantes de una comunidad (Vásquez Barquero, 2007), generándose así aspectos como una visión compartida o un ideal comunitario.

El uso de los recursos arqueológicos para el desarrollo local no es un tema fácil de abordar, ya que dependiendo del punto de vista, o el profesional que lo haga, las posiciones pueden variar y llegar a ser tensas (Gould, 2015). Y la discusión puede darse por la perspectiva de qué se entiende por bienes arqueológicos, donde existen organizaciones internacionales como la UNESCO que plantea que son herencias y parte del patrimonio de cada comunidad, por lo cual los Estados tienen la obligación de protegerlos y conservarlos (UNESCO, 1999). Otras posiciones más cercanas a las ciencias sociales o económicas le atribuyen el concepto 
de recursos, siendo entonces bienes que pueden ser utilizados de manera productiva. En este sentido, Boiser (1997) señala los recursos endógenos para el desarrollo local, donde los bienes arqueológicos podrían perfectamente ser un recurso adecuado para este objetivo. No obstante la necesidad de uso, y por muy loable que pueda ser su fin, es necesario considerar la conservación y protección de los mismos con una mirada sostenible para evitar su destrucción (Observatorio de la Sostenibilidad en España [OSE], 2009), cualquiera sea su naturaleza como patrimonio que son.

\subsection{Turismo y arqueología en Petorca}

La provincia de Petorca es un territorio con una problemática compleja por sus recursos hídricos. Éstos son cada vez más escasos, derivados de problemas naturales como la reducción de lluvias las últimas décadas, y otros efectos antrópicos como el uso poco sustentable del recurso por parte de la agroindustria (Panez-Pinto et al., 2017), además de otras actividades ilegales que, en suma, han generado una crisis productiva en la zona. Esta crisis obliga a pensar en nuevas estrategias de intervención, y la búsqueda de opciones para el desarrollo productivo local, donde el patrimonio arqueológico podría ser un recurso importante para nuevos modelos productivos, con actividades ligadas a los servicios e intangibles, en la búsqueda de un desarrollo arraigado en la realidad local (Alburquerque, 2004), descentralizándose y buscando soluciones adecuadas a sus propias problemáticas.

El uso del patrimonio arqueológico en el turismo conlleva algunos desafíos importantes como la puesta en valor del mismo (Trigueros Boto, 2016), ya que son bienes culturales que deben ser tratados con sus respectivas necesidades de cuidado y uso. No todos los bienes arqueológicos deberían estar al servicio de la actividad turística y podría ser un error intentar disponer de todos ellos como un atractivo para desarrollar oferta (Moreno Melgarejo y Sariego López, 2017), lo que tiende a darse debido a que suelen estar rodeados de un interés llamativo por lo que podrían significar o representar. En este sentido, llegar al uso turístico debería comenzar por la puesta en valor local de los bienes arqueológicos, y para eso el rol de la comunidad puede ser clave en la conservación, a través de su incorporación en los procesos de participación social y la toma de decisiones del territorio (Narváez, 2015), permitiéndoles ser protectores de su propio patrimonio arqueológico. Para esto se hace necesario algunas acciones de gestión relevantes, como lo plantea Trigueros Boto (2016), entre las que se destacan la legislación y normas jurídicas, el apoyo del sector público, investigación arqueológica y musealización, adecuación y acceso a los sitios, la educación y otras más específicas como la incorporación de las tecnologías.

Para el caso de Petorca, estudios relacionados con la arqueología local planteaban la necesidad de participación social y de monitoreo de los recursos arqueológicos (Avalos González y Ladrón de Guevara González, 2000), entendiendo la necesidad de buscar nuevas alternativas en las cuales la arqueología se integre con el desarrollo local. Además, se manifiesta el riesgo que tiene el patrimonio arqueológico local, pues si bien las actividades como el turismo podría eventualmente generar impacto en ellos por el uso del mismo, son los riesgos "comerciales" del territorio los que más afectan la arqueología local. Éste se entiende como la venta del territorio para cualquier actividad productiva, donde los sitios y bienes arqueológicos quedan expuestos y son destruidos por el avance de proyectos inmobiliarios y de otra índole. Esto pone más urgencia a la necesidad de incorporar a la arqueología local en actividades que puedan usar estos bienes, y ser al mismo tiempo protectores de los mismos. Investigadores como Ritchie y Crouch (2003) han planteado la planificación del territorio o destino turístico desde la búsqueda de una ventaja comparativa por medio del uso sustentable de sus recursos más competitivos. En este sentido, Petorca tiene en la arqueología recursos que podrían actuar como factores de diferenciación en la construcción de actividades turísticas para el desarrollo de una oferta local innovadora desde su patrimonio, pudiendo potenciar así la construcción de un destino turístico emergente.

\subsection{Modelos de desarrollo turístico}

Desde una perspectiva económica la disyuntiva de proponer modelos de desarrollo radica entre adoptar un modelo centralizado o descentralizado. Sin embargo, esa decisión no pertenece al territorio en particular sino a un nivel de manejo político nacional. La Organización para la Cooperación y el Desarrollo Económicos [OCDE] afirma que Chile está entre los países más centralizados de la organización, junto a Grecia e Irlanda. En el 2014, los gastos subnacionales gubernamentales en Chile representaron un 3,0 \% del PIB y un 13,1\% de los gastos públicos, lo que contrasta con el promedio de la OCDE que es del 16,6 \% y del 40,2 \% respectivamente (Dazzarola, 2019).

Chile se encuentra en un proceso histórico, enfrentando preguntas centrales sobre gobernanza, su contrato 
social y modelo económico (Grupo Banco Mundial, 2021). Es por esto que la expectativa es que el país se acerque más a un modelo descentralizado, producto del nuevo orden social que se está estableciendo. La Organización Mundial de Turismo (OMT, 2012), propone dentro de los cinco pilares para hacer realidad la visión de gestión: "aprovechar el potencial único del turismo para proteger el patrimonio cultural y natural y apoyar a las comunidades tanto económica como socialmente". Esto obliga a mirar prospectivamente el potencial modelo de desarrollo para el turismo arqueológico en la zona de Petorca, revisando la posibilidad de aplicar un modelo de desarrollo económico concebido para mejorar la calidad de vida de la comunidad receptora, tal como la OMT define al turismo sustentable.

Se tiene entonces, que "las propuestas descentralizadoras aparecen como nuevas alternativas de participación democrática y de desarrollo" (Zizumbo Villarreal, 2013). Este nuevo escenario propone la inclusión de la comunidad en la definición de las directrices a seguir en materia de desarrollo territorial con el propósito de identificar sus verdaderos intereses y con ello apuntar al compromiso y participación en el desarrollo de cualquier nueva iniciativa.

Para poder desarrollar el turismo utilizando los bienes arqueológicos como recursos competitivos, es necesario analizar modelos y enfoques para el desarrollo productivo, donde se presenten alternativas para lo que podría ser una planificación posterior a nivel territorial. En el planteamiento de estos modelos existen algunos tradicionales derivados de la economía actual y la competitividad empresarial, tal es el caso de los clúster turísticos basados en la teoría de conglomerados de Porter (1990) donde se potencian las empresas locales del territorio en la búsqueda de aspectos como la reducción de costos por economías de escalas y la diferenciación de productos. Este modelo descansa en la gestión comercial y asociativa de las empresas, sin embargo, no necesariamente tienen un vínculo con la comunidad local. Por otro lado, se presentan otras visiones económicas que se relacionan con la búsqueda de sistemas de administración más cooperativos, donde las organizaciones del territorio se relacionan en base al apoyo mutuo y las acciones conjuntas (Fernández Méndez y Puig Martínez, 2002), con principios como la solidaridad, la responsabilidad, la democracia, e igualdad. Existen casos con actividades como el turismo rural, donde se ha podido aprovechar los valores sociales para el fortalecimiento del turismo y a la larga ser competitivos en la oferta local. A esto se suma la visión de una economía solidaria, donde el centro del desarrollo económico está basado en las personas y en el individuo (Pastore, 2010), en una búsqueda por articular a los miembros de una comunidad, como una manera de potenciarlos para que puedan aprovechar los esfuerzos de todos, poniendo los objetivos sociales comunitarios como el fin último (Coraggio, 2020), alejándose de la visión económica tradicional en la que el capital es el eje de las operaciones y los esfuerzos productivos. En cualquier caso, la búsqueda de un modelo de desarrollo que mezcla las dimensiones espaciales, del entorno y lo económico-productivo será complejo (Osorio-García, 2006), y la planificación del desarrollo de un turismo arqueológico implicará discutir desde éstos y otros ámbitos que se relacionarán frecuentemente.

La cuestión del patrimonio arqueológico y el desarrollo local, basado en actividades como el turismo, implican entonces, y según lo analizado anteriormente, comprender la valorización social que se tiene de estos bienes culturales (Velasco Salinas, 2020) que constituirían el recurso central del desarrollo endógeno alternativo para Petorca. Moreno Melgarejo y Sariego López (2017) hacen referencia a cómo la arqueología puede hoy ser parte del desarrollo económico local, llevando incluso a que los profesionales de dicha área vean no solo en la investigación las necesidades de su financiamiento para sus acciones en los territorios, sino además, la posibilidad de abrirse a alternativas más de gestión de este patrimonio, que apunten a otras áreas donde el turismo es sin duda una oportunidad. Los bienes arqueológicos son entonces recursos valorados, y lo importante es partir analizando si son valorizaciones económicas como las ya definidas antes, u otras más bien de pertenencia social o simbólica de una comunidad, para sobre esto discutir modelos o visiones del desarrollo local que los integre.

\section{Metodología}

El estudio se basa en una investigación mixta en cuanto a la recopilación de antecedentes (Hernández Sampieri et al., 2014), para obtener información cuantitativa y cualitativa asociada a la valorización social del patrimonio y el desarrollo turístico local. En primer lugar, se realiza un análisis descriptivo del patrimonio arqueológico de Petorca, basado en un trabajo en terreno, sumado a una revisión del contexto turístico local con base en información relacionada con oferta y demanda, para tener una visión general del sector. Con esto se obtiene un panorama del patrimonio arqueológico local y el desarrollo actual del sector turístico.

Se suma un carácter exploratorio y descriptivo en la búsqueda de visiones relacionadas con el desarrollo te- 
rritorial, con énfasis en el uso y valoración del patrimonio. Para ello se realizó una encuesta a un total de 84 personas sobre un universo total de 78.299 habitantes de la provincia de Petorca, donde la cantidad necesaria para un $95 \%$ de confianza y un $5 \%$ de error correspondería a 383 habitantes, y para una muestra con un $10 \%$ de error sería de 68 habitantes. El contenido de dicho instrumento está compuesto en su totalidad por nueve preguntas cerradas de selección múltiple, las cuales se subdividen en: tres preguntas de identificación general del encuestado, dos preguntas de reconocimiento del patrimonio arqueológico en la provincia, una de valoración del mismo patrimonio, y finalmente tres preguntas sobre las preferencias de la comunidad respecto a un potencial desarrollo del turismo arqueológico. Esto último busca obtener información cualitativa principalmente relacionada con aspectos de percepción y valoración del patrimonio arqueológico local.

Por otro lado, para la generación de parámetros cuantitativos, y con el objetivo de graficar de mejor forma el estado actual de los principales sitios arqueológicos y las zonas generales, y su ubicación en la provincia de Petorca, se determinó una calificación porcentual, a través de algunas variaciones a la metodología desarrollada por Manzato y Rejowski (2007), la cual califica el potencial desarrollo arqueoturístico analizando el estado de São Paulo, Brasil. Dicha investigación, determinó el estado en que cada sitio se encuentra, según la calificación de los visitantes de los distintos sitios ubicados en el estado brasilero. En su investigación los autores proponen una ecuación para determinar a nivel general las condiciones del territorio para el desarrollo del turismo con base en la arqueología (ecuación [1]).

$$
E=(S M A \times 100) / T
$$

donde:

- $\quad E=$ Índice de adecuación arqueoturístico (porcentaje)

- $\quad S M A=$ Sitios muy adecuados (número)

- $T=$ Total de sitios arqueoturísticos del Estado (número).

Para este estudio, la calificación de cada sitio se determinó a través de las indicaciones y percepciones entregadas en las entrevistas realizadas a los distintos actores claves. Por esta razón, es oportuno reconocer la posibilidad de existencia de sesgos o limitaciones de percepción, ya que si bien las evaluaciones fueron efectuadas con base en la percepción de involucrados calificados en el tema, corresponden a impresiones particulares y no una evaluación absoluta en el área. Aún así, parte de este estudio al ser exploratorio buscaba evaluar este tipo de percepciones personales, en línea con aquello que Alburquerque (2004) señalara como democratización del territorio, y en este sentido comprender cómo perciben y cualifican su patrimonio estos actores locales.

En una escala de 1 a 100, donde 1 es la más baja y 100 la calificación más alta, se evaluaron los ocho principales sitios ubicados en la provincia de Petorca. A su vez, se establecieron cinco categorías de evaluación con distintos valores de ponderación, correspondientes a su importancia para el desarrollo arqueoturístico, tanto en aspectos como el valor arqueológico y estado actual del recurso como las capacidades turísticas del sitio en general. Dichas categorías de evaluación ponderada son:

- Valor arqueológico (30 \%)

- Estado de conservación $(20 \%)$

- Equipamiento turístico del sector (30\%)

- $\quad$ Accesibilidad al sitio (10\%)

- $\quad$ Difusión del sitio (10\%)

De esta forma, según la calificación obtenida por cada sitio, se asignó el nivel situacional actual de cada sitio de la provincia, pudiendo desglosarse en:

- $\quad$ Adecuada (80-100)

- Intermedio avanzado (50-79)

- Intermedio básico (20-49)

- $\quad$ Inicial (1-19) 
Finalmente, para determinar el estado general de la provincia de Petorca, en cuanto al desarrollo de turismo arqueológico, se utilizó la misma fórmula establecida por Manzato y Rejowski (2007), donde las calificaciones posibles de obtener son:

- $E=80 \%$ a $100 \% \Rightarrow$ Estado avanzado de explotación turística

- $E=50 \%$ a $79 \% \Rightarrow$ Estado intermedio de explotación turística

- $E=20 \%$ a $49 \% \Rightarrow$ Estado inicial de explotación turística

- $E=1 \%$ a $19 \% \Rightarrow$ Estado inexistente de explotación turística

Con esto se logra establecer el grado de valorización social que existe en Petorca acerca de su patrimonio arqueológico, y el nivel de desarrollo del turismo vinculado a dichos bienes culturales locales.

\section{Resultados}

\subsection{El sector turístico actual en el territorio}

El territorio provincial en su gran mayoría, y sobre todo la zona interior de éste, no está considerado en la actualidad dentro de los destinos turísticos más reconocidos y efectivamente preparados para la actividad turística en la zona, según el informe de intensidad turística y definición de destinos turísticos (Subsecretaría de Turismo, 2018). Dicho informe tiene por objetivo determinar a través de variables de oferta y demanda el comportamiento turístico de los territorios del país. Por un lado, en las comunas costeras de Papudo y Zapallar se destaca el reconocido destino "Litoral Norte" como un destino ya consolidado. Por otro lado, sitúa y propone como potencial destino turístico rural el destino "La Ligua-Valle Hermoso", debido al potencial de los atractivos, pero deficientes labores administrativas, de infraestructura y de servicios en la zona.

Es precisamente el turismo rural una de las tipologías que ha tomado más fuerza y experimentado una mayor notoriedad dentro de las comunas interiores de la provincia. Dentro de la capital provincial, es posible mencionar las rutas "La Ligua, de Campo a Mar" y "Ruta Rural", la primera de ellas impulsada por el municipio local, que comienza con un desayuno y degustaciones de productos elaborados por pequeños productores locales, para luego dar paso a un recorrido por el barrio comercial de Valle Hermoso para finalizar en el sector costero de la comuna. En el mismo sentido, la segunda ruta tiene su enfoque en el proceso de hilado de lana de alpacas, como talleres para el uso de plantas medicinales. En el caso de la comuna de Cabildo, se señalan intentos aún de estudio y reconocimiento de la dinámica turística en la zona. Tal es el caso de la organización de pequeñas visitas guiadas por el sector de Alicahue, zona llamada a ser el "bastión" del desarrollo turístico de la comuna. Dichas actividades, según la encargada de la Unidad de Deportes, Turismo, Cultura y Recreación del municipio local, consisten en visitas a diferentes productores y atractivos de la zona como los recorridos por el teatro y el museo arqueológico de Alicahue, como también, desde una perspectiva aglutinadora de emprendedores locales, visitas a restaurantes criollos, lechería, talleres y muestra de procesos de producción de carbón, talabartería y apicultura (M. Madariaga, comunicación personal, 26 noviembre de 2020).

Por último, la ruta turística "Donde el diablo perdió el poncho" es un producto ya elaborado y puesto en marcha impulsado por el Municipio de Petorca y el Instituto de Desarrollo Agropecuario [INDAP], el cual reúne, muestra y pone en valor componentes rurales, artesanales, gastronómicos, paisajísticos y culturales de la comuna. En explicación del departamento de Turismo del Municipio de Petorca, la ruta sugiere, además, alojamiento, restaurantes y panoramas extras, proporcionando una oferta completa y diversa al turista que llegue al lugar (C. Segura, comunicación personal, 25 de niviembre de 2020).

En cuanto a las capacidades instaladas en el territorio, existen registrados en el Servicio Nacional de Turismo [SERNATUR], solo 27 alojamientos, en diversas categorías, de un total de 68 empresas ${ }^{1}$. En el caso del área de alimentación, de un total de 158 empresas existentes, solo 27 se encuentran registradas. Por parte de las empresas dedicadas a la intermediación como operadores turísticos existen solo siete empresas, tres de las cuales están registradas en el registro nacional, y además solo cuatro de ellas han realizado actividades en sitios relacio-

1 No todas las empresas formalizadas están inscritas en los registros nacionales de prestadores de servicios que tiene el SERNATUR, lo que refleja el grado de irregularidad de algunos prestadores locales. 
nados con el patrimonio arqueológico. Finalmente existen 22 empresas registradas con actividades de turismo en terreno, principalmente en la costa en actividades como buceo, cabalgatas, kayak de mar o canotaje, y de ellas solo 15 están registradas como operadores de dichas actividades en turismo. En síntesis, se refleja un desarrollo de servicios y actividades principalmente en la costa de la provincia, con actividades ligadas al turismo de sol y playas, y en menor proporción algunas actividades ligadas al sector rural en la zona interior del territorio.

Finalmente a nivel de la infraestructura, las comunas cuentan con servicios generales de comunicaciones, transporte y servicios básicos de energía, salud o servicios sanitarios sobre el $95 \%$ de cobertura en la mayoría de los territorios que componen la provincia.

\subsection{La arqueología local para el desarrollo del turismo arqueológico}

De mar a cordillera, distintos sitios arqueológicos de diferente dimensión y significancia grafican un pasado heterogéneo, poco divulgado y conservado, pero de suma importancia para el desarrollo sociocultural de los habitantes del territorio y la comunidad en general. Al hacer un barrido por las distintas áreas vinculadas al patrimonio arqueológico de la zona, se puede encontrar, en primer lugar, dos instituciones formales que juegan un importante rol en la conservación, educación y divulgación del patrimonio cultural provincial, siendo el patrimonio arqueológico una arista importante de éste. Primero, el museo La Ligua, dependiente de la Ilustre Municipalidad de La Ligua, figura como el principal ente impulsor y gestor de dicho patrimonio. Dentro de la colección destacan piezas del tipo arqueológicas (Figura 1), históricas y etnográficas de distintas partes del territorio provincial. La segunda entidad vinculada al rescate y divulgación del patrimonio arqueológico corresponde al museo Alicahue, ubicado en la comuna de Cabildo, enfocado en el resguardo de los vestigios arqueológicos de diversa índole hallados en el valle de Alicahue, representando sin duda una rica e importante zona de interés arqueológico dentro de la provincia. Dentro de los vestigios arqueológicos encontrados en este valle cordillerano de la provincia, es posible distinguir dos sobresalientes hallazgos; por una parte, los petroglifos de Alicahue ubicados en zonas de complejo acceso y accidentadas condiciones geográficas, configuran una particularidad y belleza inusual en la zona, con la representación de figuras zoomorfas y abstractas, inmersas en un entorno paisajístico cordillerano característico de la zona. El segundo sitio a considerar guarda relación con los vestigios pertenecientes al Qhapaq Nan o Camino del Inca en el período tardío (1430 d. C. - 1540 d. C.), dicho recurso expone y respalda el pasado territorial con influencia incaica de la zona (Consejo de Monumentos, 2015), que forma parte importante del pasado histórico provincial y toma como base los testimonios materiales encontrados en la zona. Su difícil acceso, junto a la situación crítica en la cual se encuentran respecto al grado de conservación y preservación, hacen de estos sitios un desafío complejo, pero a su vez atractivo e importante de considerar para el turismo.

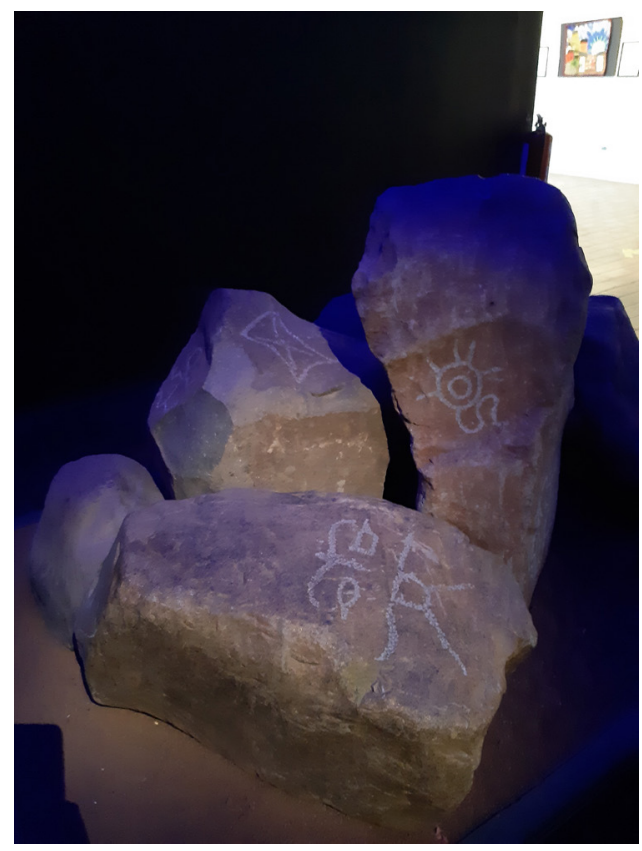

Figura 1. Muestra arquelógica del museo La Ligua. Figure 1. Archaeological sample of the La Ligua museum. 
Continuando en el sector interior de la provincia, los dos siguientes sitios arqueológicos ubicados esta vez en la comuna de Petorca figuran dentro del patrimonio arqueológico de mayor reconocimiento a nivel provincial. La huella de culturas preincaicas que habitaron el territorio en cuestión, dotan y estructuran la zona en un polo importante para el desarrollo investigativo-arqueológico, también con fines divulgativos sobre el valor del patrimonio cultural desde todas sus dimensiones. En el caso de los sitios arqueológicos en Petorca, es posible asociarlas en gran medida a representaciones antropomorfas, ceremoniales y a expresiones sobre la cosmovisión.

El sitio arqueológico El Pedernal en la comuna de Petorca, conforma un campo de alta concentración de petroglifos (Figura 2) en un espacio aproximado de dos hectáreas, con alrededor de 54 bloques de petroglifos. Cercano al anterior punto, en el sector de Chalaco, el sitio arqueológico Quebrada la Monhuaca a 17 kilómetros del centro urbano de Petorca, posee un afloramiento rocoso en el cual se encuentra un número cercano a 20 bloques con representaciones zoomorfas y geométricas figurativas (Figura 3), junto con material lítico y cerámico. Según los trabajos realizadas en el sector, el sitio en específico corresponde a un lugar de culto prehispánico debido a su ubicación y motivo de las representaciones.

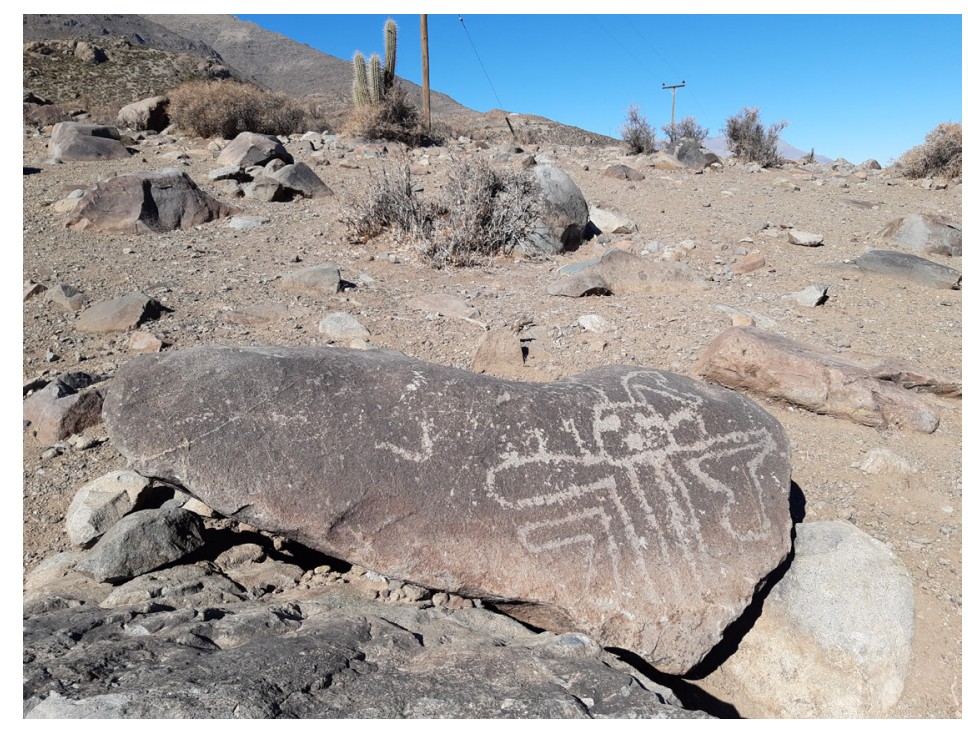

Figura 2. Petroglifos sector El Pedernal, comuna de Petorca. Figure 2. Petroglyph of El Pedernal sector, Petorca commune.

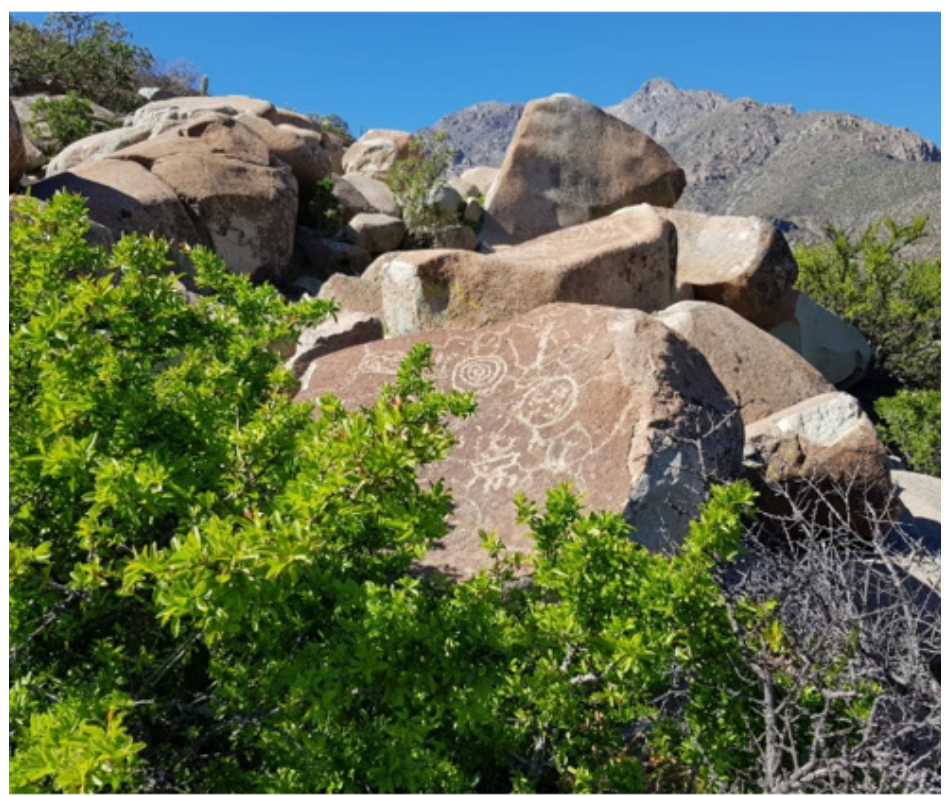

Figura 3. Petroglifo, sector Chalaco, quebrada La Monhuaca, Petorca. Figure 3. Petroglyph of Chalaco sector, quebrada La Monhuaca, Petorca. 
Por último, la zona costera de la provincia destaca por poseer un reconocido yacimiento arqueológico inmerso dentro de un particular entorno. Situado entre las desembocaduras de los ríos La Ligua y Petorca, el sitio arqueológico Dunas de Longotoma, es uno de los sitios con mayor presencia dentro del colectivo ciudadano, ayudado sin duda por su ubicación dentro de un campo dunar con características naturales y climáticas particulares. Dentro de los vestigios encontrados en el área, existen residuos malacológicos (popularmente conocidos como conchales) (Figura 4), material cerámico, tembetás, entre otras. Según las investigaciones propias del sector, permiten adjudicar todos los restos encontrados al complejo cultural Bato, fechados en el 290-170 d. C., aproximadamente. Kilómetros más al norte, en el sector costero de Los Molles perteneciente a la comuna de La Ligua, se encuentran una serie de yacimientos, entre los cuales se localiza el sitio Los Molles 115, Los Coiles 136 y El Chivato, siendo este último el más destacado al establecer según las distintas investigaciones realizadas en el sector, un ocupamiento parcial en la zona desde hace 8.000 años (Avalos González et al., 1997).

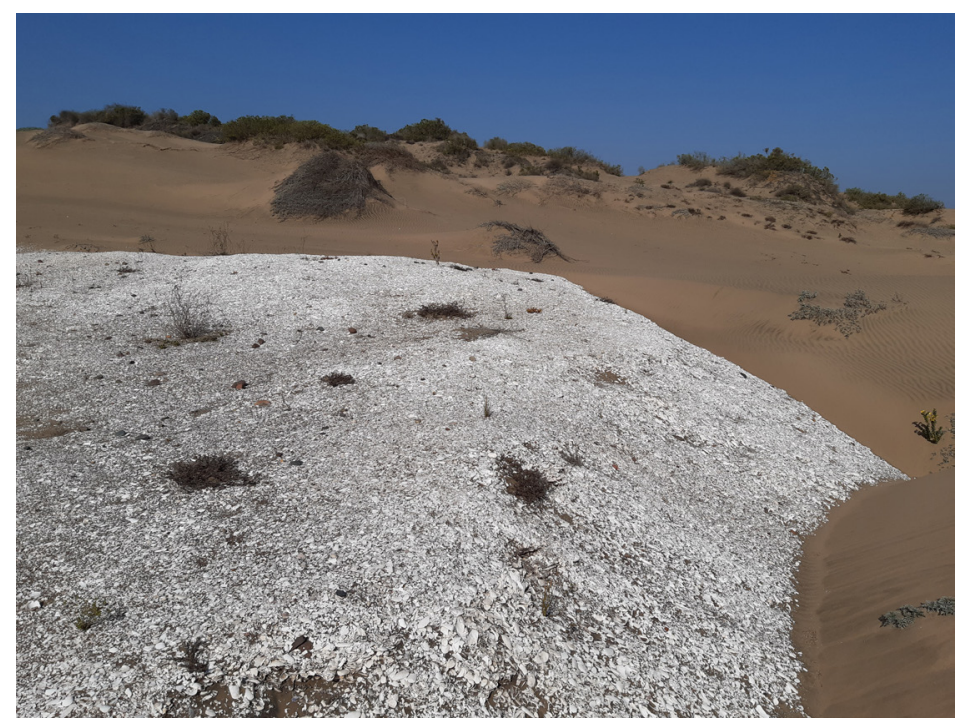

Figura 4. Residos malacológicos, dunas de Longotoma entre La Ligua y Petorca. Figure 4. Malacological remains, Longotoma dunes between La Ligua and Petorca.

\subsection{Evaluación de los sitios para uso turístico}

Al aplicar la metodología trabajada por Manzato y Rejowski (2007) a los sitios y bienes locales, desde la perspectiva de su adecuación para un turismo arqueológico, los resultados son presentados en la Tabla 1.

Tabla 1. Evaluación del patrimonio arqueológico con base en categorías relacionadas al sector turístico.

Table 1. Assesment of the archaeological heritage based on categories related to tourism.

\begin{tabular}{|c|c|c|c|c|c|c|}
\hline Sitio Arqueológico & $\begin{array}{c}\text { Valor } \\
\text { Arqueológico } \\
(30 \%)\end{array}$ & $\begin{array}{c}\text { Estado de } \\
\text { Conservación } \\
(20 \%)\end{array}$ & $\begin{array}{c}\text { Equipamiento } \\
\text { Turístico } \\
(30 \%)\end{array}$ & $\begin{array}{l}\text { Accesibilidad } \\
\qquad(10 \%)\end{array}$ & $\begin{array}{c}\text { Di- } \\
\text { fusión } \\
(10 \%)\end{array}$ & Total \\
\hline Dunas de Longotoma & 40 & 20 & 70 & 80 & 60 & 51 \\
\hline El Chivato, Los Molles & 40 & 10 & 40 & 20 & 10 & 29 \\
\hline Museo La Ligua & 70 & 90 & 80 & 100 & 80 & 81 \\
\hline Petroglifos "El Arenal" & 60 & 20 & 30 & 30 & 60 & 40 \\
\hline $\begin{array}{l}\text { Petroglifos Quebrada "La } \\
\text { Monhuaca" }\end{array}$ & 60 & 20 & 40 & 40 & 40 & 42 \\
\hline Camino del Inca & 50 & 10 & 10 & 10 & 10 & 22 \\
\hline Petroglifos Alicahue & 40 & 10 & 10 & 10 & 10 & 19 \\
\hline Museo Alicahue & 50 & 70 & 30 & 40 & 40 & 46 \\
\hline
\end{tabular}


Según las calificaciones otorgadas a cada sitio, el museo de La Ligua registró la mejor puntuación, pudiendo encasillarse dentro de un nivel adecuado para el desarrollo del turismo en la provincia. Por lo contrario, el sitio Camino del Inca, junto a los petroglifos de Alicahue, ambos ubicados en la comuna de Cabildo, obtuvieron las calificaciones más bajas, debido principalmente a su condición de difícil acceso, desprotección del recurso arqueológico y bajo desarrollo turístico en general de su entorno.

Al dividir el territorio, el sector costero junto al museo La Ligua se sitúa en mejor pie para el desarrollo turístico en la provincia, ayudado principalmente por el desarrollo en el equipamiento e infraestructura turística en general de la zona costera, no obstante, se deben establecer objetivos de perfeccionamiento a futuro en temas de conservación y acceso a los diferentes sitios, ya que, si bien el sitio Dunas de Longotoma califica dentro del intervalo intermedio avanzado, aún falta desarrollo local. Los sitios de la comuna de Petorca, al calificar ambos dentro de la categoría intermedio-básico, sus principales objetivos están determinados en mejorar las condiciones de acceso, aumento regulado, pero diverso de la planta turística, y optimizar los mecanismos de conservación y preservación de los sitios. Por último, como ya se ha mencionado, la comuna de Cabildo se encuentra en una situación incipiente para el desarrollo de un turismo arqueológico, por lo que las oportunidades de mejora son amplias. Sin embargo, no se avizora un desarrollo de corto a mediano plazo, si es que las instituciones encargadas de fomentar el área no generan un trabajo sistemático y concreto en los sitios señalados, ni se mejoran las condiciones generales para el desarrollo del turismo que debiera ser sustentable para garantizar la sostenibilidad dentro de la comuna. De este modo, realizando el cálculo (ecuación [2]), el resultado es:

$$
E=(1 \times 100) / 8=12,5
$$

El estado general de la provincia de Petorca, para el desarrollo de turismo arqueológico, es de una etapa inicial, donde los principales objetivos a trabajar deberían estar, en primer lugar, en asegurar una conservación y protección de los sitios arqueológicos del territorio, a través de iniciativas específicas, y segundo, mejorar las condiciones de planta e infraestructura para el avance turístico en general.

\subsection{La valorización social del patrimonio arqueológico}

El análisis del territorio comprende cinco comunas que confluyen en un mismo espacio geográfico (Figura 5), lo que implica que las personas que habitan en este lugar tienden a tener flujos de intercambios diarios relacionados con su trabajo, educación, comercio y transporte, entre otras instancias de intercambio social. Esto refleja que el universo en estudio constituye una comunidad con rasgos similares en ciertos aspectos básicos asociados al lugar donde cohabitan (Velásquez, 2001), por ende, pueden ser tratados como una comunidad que cohabita su territorio. Algunos datos de esta comunidad local se presentan a continuación.

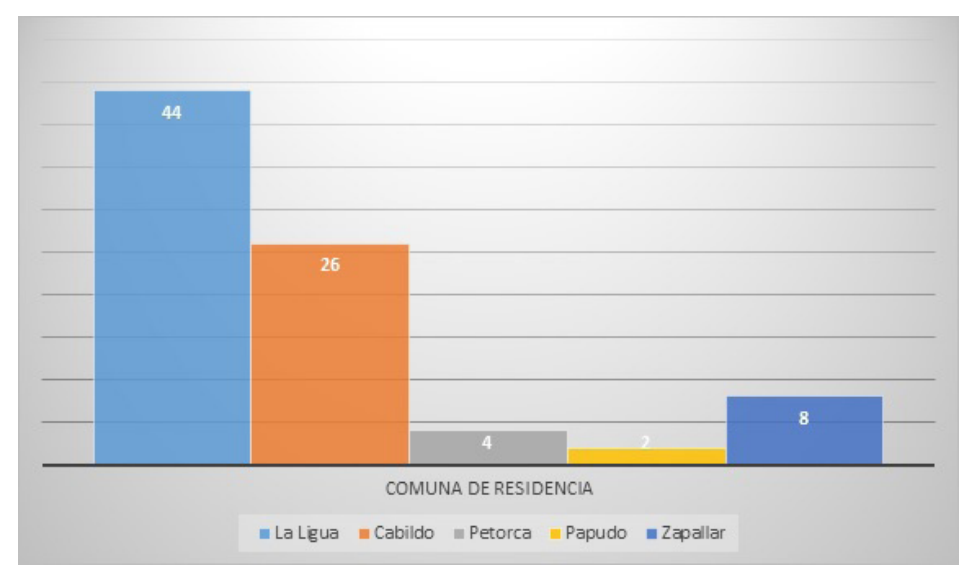

Figura 5. Comunas de residencia de los entrevistados.

Figure 5. Respondents' communities of residence. 
En cuanto al género, el $52 \%$ son mujeres, un $47 \%$ hombres y un $1 \%$ se identifica en otra categoría. Por otro lado, las edades de los mismo se centran en su mayoría entre los grupos de adultos jóvenes y adultos (Figura 6). Respecto a los principales sitios y bienes arqueológicos que existen en el territorio, se buscó determinar el grado de conocimiento de este patrimonio en la provincia por parte de la propia comunidad local, consultando por aquellos que han sido visitados (Figura 7).

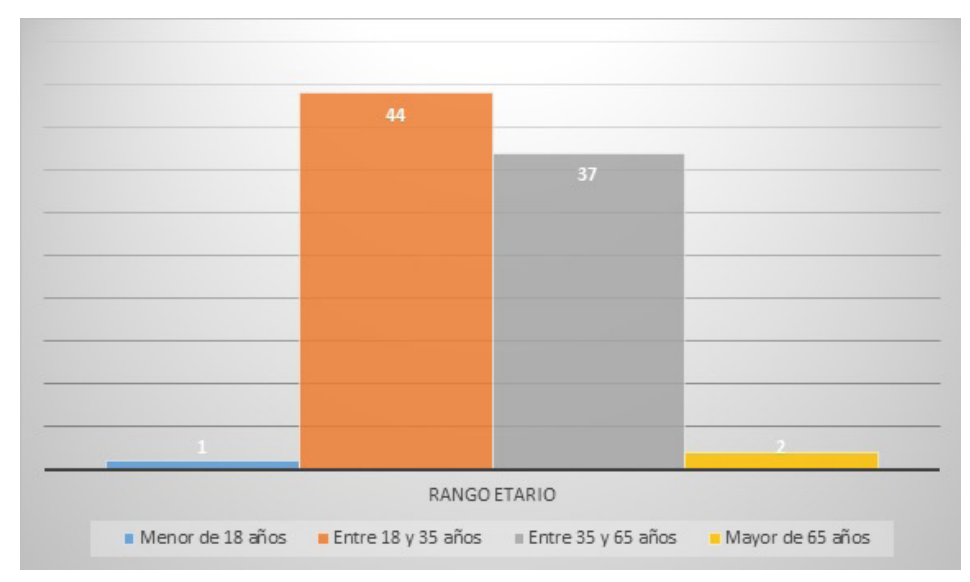

Figura 6. Edad de los entrevistados.

Figure 6. Respondents'age.

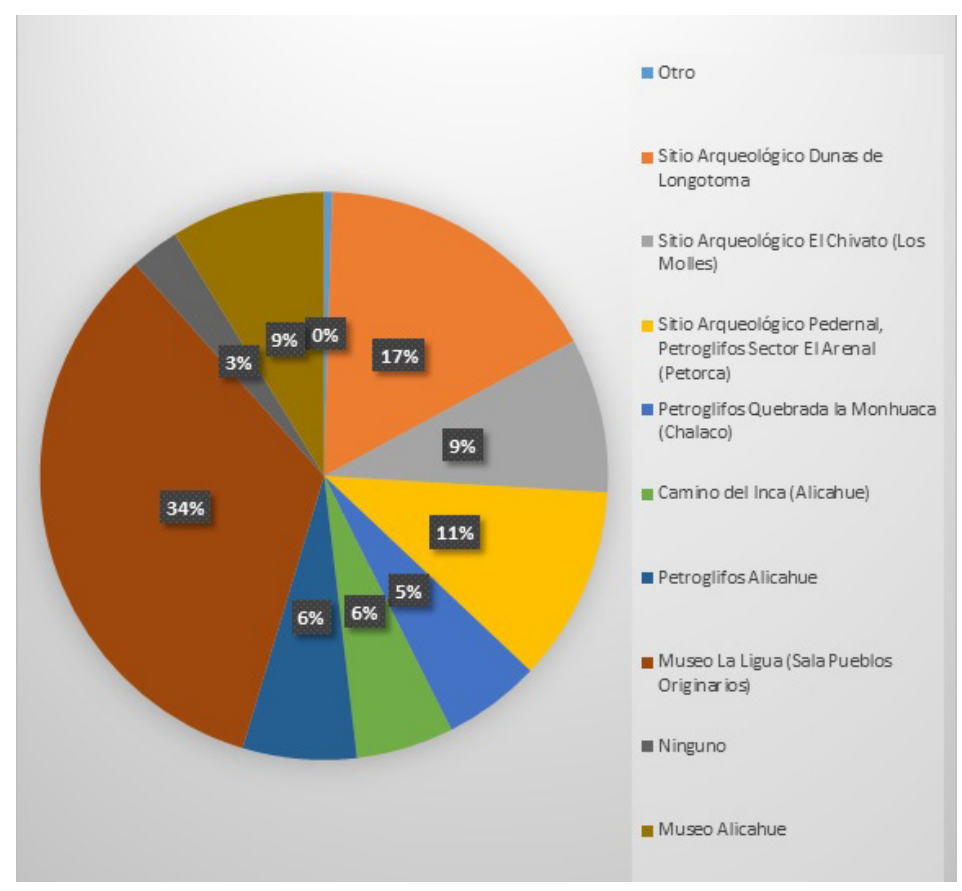

Figura 7. Sitios y bienes arqueológicos más visitados por la comunidad. Figure 7. Archaeological sites and assets most visited by the community.

Los resultados arrojan una mayoría de visitas al museo de La Ligua (Figura 8), que concentra una cantidad importante de bienes arqueológicos locales, además de otros recursos culturales. Luego, las Dunas de Longotoma son mencionadas también como sitio reconocido y visitado. En tercer lugar están los petroglifos del sector El Arenal y luego se distribuyen otros sitios con menor participación. Es importante mencionar que el museo de La Ligua, ubicado en la capital de la provincia, es un lugar público, ubicado en un centro urbano y con difusión 
permanente, por tanto es lógico la mención del mismo por sobre otros sitios y bienes que no tienen una estructura de gestión como recursos patrimoniales. Ahora bien, al ser consultados por aquellos sitios que les llaman la atención y que les gustaría conocer en su provincia, los resultados muestran una clara preferencia a los petroglifos y el Camino del Inca, relievando lo llamativos que son este tipo de recursos entre la comunidad, algunos de los cuales son señalados como "sin conocimiento" de su existencia entre los mismos habitantes locales.

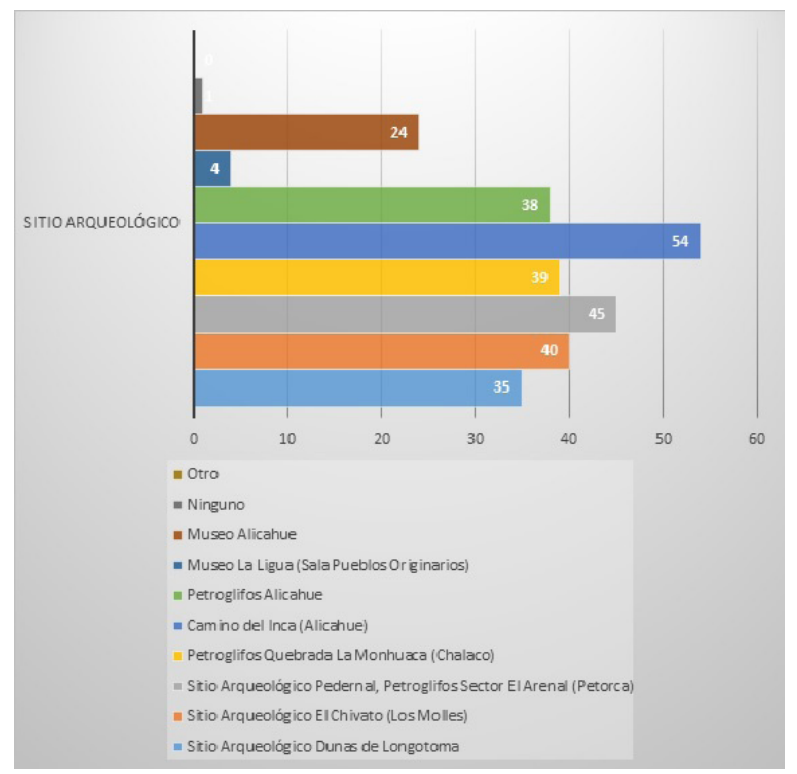

Figura 8. Sitios que le gustaría conocer en la provincia.

Figure 8. Sites to visit in the province.

Finalmente, se buscó conocer el valor que le asignan como habitantes al patrimonio arqueológico de su provincia por medio de una escala de apreciación de 1 a 5, basado en la información y conocimiento que cada persona tiene, sin más intuición que su perspectiva personal (Figura 9).

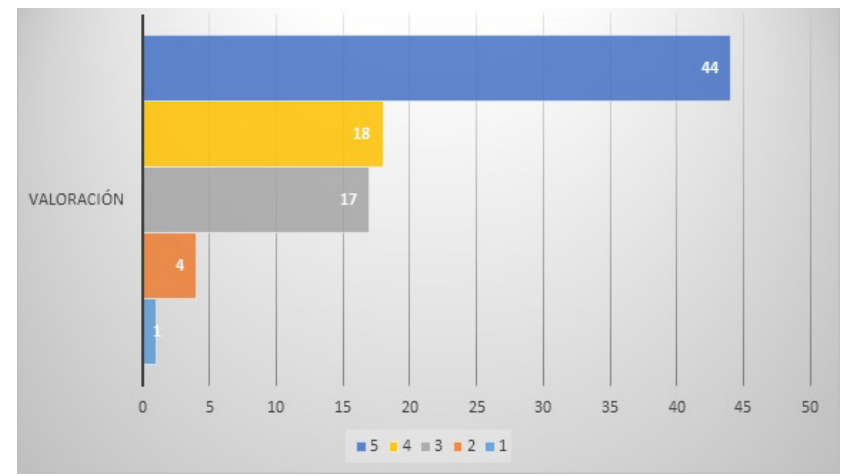

Figura 9. Valorización de los habitantes respecto al patrimonio arqueológico local.

Figure 9. Social valorization of local archaeological heritage by inhabitants.

Al hacer referencia al conocimiento de la población provincial sobre el patrimonio arqueológico, por amplia preferencia el lugar con mayor reconocimientos y visitas lo obtiene el museo La Ligua. Esta notoria diferencia se debe, en parte, al tratarse de una organización amparada bajo una institucionalidad comunal, quien la dota de mayores herramientas y facultades para posicionarse como actor principal en el área arqueológica. El resto de sitios existentes dentro de la provincia registran valores relativamente cercanos. El sitio arqueológico Dunas de Longotoma, sin embargo, si bien no registra una clara distancia, destaca como el segundo sitio con mayor reconocimiento, posiblemente debido a un incipiente desarrollo turístico en el sector, dándole de este modo 
mayor difusión para su reconocimiento. En cuanto a la intención de los habitantes por visitar los sitios arqueológicos, los sectores interiores de la provincia y en especial los ubicados en el sector de Alicahue, comuna de Cabildo, son elegidos como los principales generadores de motivación para su conocimiento. La explicación más coherente para ello, se debe a un menor desarrollo turístico y puesta en valor del sector, disminuyendo las posibilidades de acceso, y por consiguiente generando desconocimiento dentro de la población

Ante algunas consultas realizadas respecto al desarrollo turístico del territorio con base en el uso del patrimonio arqueológico local, los resultados mencionan dos áreas preferentes al respecto. Primero, un enfoque deportivo como el ya desarrollado de forma inicial en los sectores costeros, pero ahora en diferentes sitios de la provincia. Esto se enfoca en actividades vinculadas a caminatas o recorridos guiados por cerros y campos dunares. En segundo ámbito, un enfoque educativo con actividades relacionadas directamente con el aprendizaje sobre los bienes como recursos culturales históricos.

Respecto a la valorización del patrimonio, una amplia mayoría señala el patrimonio arqueológico con la más alta valoración histórica, científica y cultural del recurso. Se evidencia de esta manera la urgencia en el desarrollo de instrumentos para el resguardo y conservación de los bienes ante las numerosas amenazas de distinta índole que pueden acabar con este valioso patrimonio.

\section{Discusión}

Es interesante un modelo alternativo que parta desde la democratización del territorio (Alburquerque, 2004), con una priorización hacia el uso de los recursos endógenos. Esto implica, primero, la puesta en valor del patrimonio local, entendiéndolo como la apropiación social de dichos bienes por parte de los habitantes, reconociéndolos como un factor importante para su propio bienestar. Si la comunidad lograra conocer adecuadamente este patrimonio, podrían valorarlo, quererlo y actuar de manera cohesionada para garantizar así la conservación del mismo. Esta es la base de un modelo formado desde el desarrollo local, que si se mira con claridad, requiere de educación innovadora, interactiva, con medios adecuados a la realidad actual, que permitan llamar la atención de la gente, sobre todo los más jóvenes, para lo cual, herramientas como las tecnologías digitales pueden ser un recurso importante para conseguir esos resultados.

Desde la mirada productiva, el desarrollo turístico local debiera estar enfocado en generar un sistema de producción con actividades especializadas, donde el foco esté puesto en la generación de oferta innovadora, con productos y servicios basados en la educación y la experiencia, proponiendo momentos memorables y de aprendizaje para el visitante y aportes concretos para el habitante local en aspectos como la creación de empleos, emprendimientos y asociatividad. Tal como la economía básica, generar una oferta para responder a una demanda de experiencias turísticas, pero en este caso poniendo énfasis en las personas, no solo en el capital como factor productivo principal. El emprendimiento debiera estar priorizado en los esfuerzos públicos, para incentivar la participación de los miembros de la comunidad en la generación de negocios pequeños (Zizumbo Villarreal, 2013). Algunas opciones son circuitos temáticos con relatos locales, donde la arqueología permita evidenciar un pasado significativo del territorio. Además, visitas con el uso de tecnologías que complementen la experiencia del visitante con foco en el aprendizaje interactivo. La cercanía de la provincia con la región metropolitana permite suponer la facilidad de llegada de este principal destino emisor de visitantes, por tanto, la gestión comercial no debiera ser un aspecto complejo, sobre todo si la oferta se centra en la creación de experiencias auténticas, ligadas a la arqueología con servicios sencillos de implementar (para fomentar el emprendimiento a pequeña escala), pero con fuerza en el relato auténtico.

Por último, el sector público juega un rol fundamental, ya que debiera ser el articulador entre la comunidad del territorio y otras organizacions privadas como el sector turístico actual, otros sectores asociados como el comercio y el transporte, los medios de comunicación, entre otros. La construcción de un modelo arraigado en las características propias de la provincia de Petorca, requiere del compromiso político de las autoridades de cada unidad territorial que la conforman, poniendo a las personas en el centro, y el turismo como una oportunidad para utilizar el patrimonio arqueológico como factor de desarrollo local.

\section{Conclusiones}

Un territorio como el que comprende la provincia de Petorca requiere proyectar escenarios alternativos para su desarrollo futuro. El panorama actual es complejo por la escasez hídrica, sumado a la existencia de activi- 
dades productivas tradicionales que no han logrado un desarrollo local efectivo. En este sentido, los recursos patrimoniales ligados a la arqueología pueden ser una oportunidad para mirar alternativas de desarrollo, con actividades como el turismo que aún no han sido explotadas en la zona.

El patrimonio arqueológico de la provincia de Petorca puede ser un recurso relevante en el desarrollo del turismo local, sobre todo por la valorización social que tiene. Esto implica un trabajo de difusión del mismo entre la comunidad, desde distintas perspectivas que muestren las oportunidades que estos recursos ofrecen por medio de su uso de manera sustentable. Además, son las mismas personas quienes podrían actuar como medios de conservación si se considera su participación en los procesos de desarrollo de oferta, por medio del emprendimiento a menor escala y el encadenamiento de servicios entre los miembros de la comunidad.

El estado actual de los sitios y bienes arqueológicos, con base en la metodología de Manzato y Rejowski (2007), se puede establecer que están en un estado inicial para su uso turístico. Si bien esto podría desincentivar el desarrollo de productos y servicios en lo inmediato, puede ser también una oportunidad para la creación de productos innovadores, donde los bienes sean un complemento a la experiencia y no necesiariamente el fin último. Tal es el caso de servicios como recorridos deportivos (como el senderismo), donde los bienes arqueológicos pueden ser puntos complementarios a un itinerario más amplio.

Finalmente, el desarrollo turístico en territorios complejos como la provincia de Petorca, requiere buscar nuevos modelos productivos para lograr un desarrollo local, donde las actividades tradicionales pueden no ser la respuesta más adecuada. En este sentido, toman relevancia algunas acciones como el cooperativismo y la economía solidaria, donde las personas son vistas como el activo más importante y desde ellas se van conformando las iniciativas y se toman decisiones como qué productos o servicios desarrollar y a qué escala. La participación del sector público es importante para articular comunidad, empresas y otros actores locales, orientando los esfuerzos en la contrucción de un turismo que sea adecuado a la realidad y las necesidades del territorio.

\section{Agradecimientos}

Estudio derivado del proyecto de titulación denominado "Diagnóstico y lineamientos generales sobre el desarrollo del turismo arqueológico en la Provincia de Petorca" año 2020, Escuela de Gestión en turismo y cultura, Universidad de Valparaíso.

\section{Contribuciones de los autores}

- Alan Muñoz: conceptualización, análisis, redacción

- Felipe Araneda: investigación, recursos

- María Soledad Ostria: Administración, visualización

\section{Referencias}

Alburquerque, F. (2004). El enfoque del desarrollo económico local. Cuaderno de capacitación No. 1. Serie: Desarrollo Económico Local y Empleabilidad. Programa AREA - OIT en Argentina - Italia Lavoro.

Álvarez García, R. D., \& Rendón Acevedo, J. A. (2010). El territorio como factor del desarrollo. Semestre Económico, 13(27), 39-62. https://revistas.udem.edu.co/index.php/economico/article/view/256

Avalos González, H., \& Ladrón de Guevara González, B. (2000). El patrimonio cultural como bien de consumo: el caso Petorca. Conserva, 4, 87-114. https://nuevamuseologia.net/conserva-4/

Avalos González, H., Valenzuela A., E., Rodríguez L., J., \& Román B., Á. (1997). Arqueología y Estratigrafía del Holoceno de Los Molles en Chile Central: Antecedentes Paleoclimáticos. XIV Congreso Nacional de Arqueología, Copiapó, Chile. https://scha.cl/wp-content/uploads/2020/10/Actas\%20XIV\%20 Tomo\%201_Final.pdf

Boisier, S. (1997). El vuelo de una cometa. Una metáfora para una teoría del desarrollo territorial. Revista Eure, XXIII(69), 7-29. https://www.eure.cl/index.php/eure/article/view/1159/260

Consejo de Monumentos. (2015). Qhapaq Ñan. Sistema vial andino y de los incas en el norte de Chile. https:// www.monumentos.gob.cl/publicaciones/libros/qhapaq-nan-sistema-vial-andino-incas-norte-chile 
Coraggio, J. (2020). Economía social y economía popular: Conceptos básicos. Consejo Consultivo, Documento N. ${ }^{\circ} 1$, INAES/Ministerio de Desarrollo Productivo.

Dazzarola, G. (2019). Descentralización en Chile, avances y temas pendientes. Biblioteca del Congreso Nacional. https://www.bcn.cl/asesoriasparlamentarias/detalle_documento.html?id=75093

Fernández Méndez, M., \& Puig Martínez, A. (2002). El papel del cooperativismo en el turismo rural de la Comunidad Valenciana. CIRIEC-España, Revista de Economía Pública, Social y Cooperativa, 41, 183-212. http://ciriec-revistaeconomia.es/wp-content/uploads/08_Fernandez_y_Puig_41.pdf

Gould, P. G. (2015). Arqueología y desarrollo económico: un ejemplo basado en una comunidad del Perú. Revista Colombiana de Antropología, 51(2), 317-338. https://revistas.icanh.gov.co/index.php/rca/article/ view/224

Grupo Banco Mundial (2021). Chile panorama general. https://www.bancomundial.org/es/country/chile/ overview

Hernández Sampieri, R., Fernández Collado, C., \& Baptista Lucio, P. (2014). Metodología de la investigación (6. ${ }^{\mathrm{a}}$ ed.). McGraw Hill Education.

Manzato, F., \& Rejowski, M. (2007). Turismo cultural: Evaluación del potencial turístico de sitios arqueológicos. Estudios y perspectivas en turismo, 16(1), 72-95. https://www.estudiosenturismo.com.ar/search/ $\mathrm{PDF} / \mathrm{v} 16$ n1a04.pdf

Moreno Melgarejo, A., \& Sariego López, I. (2017). Relaciones entre Turismo y Arqueología: el Turismo Arqueológico, una tipología turística propia. PASOS Revista De Turismo Y Patrimonio Cultural, 15(1), 163180. https://doi.org/10.25145/j.pasos.2017.15.010

Narváez, E. L. (2015). El turismo alternativo: Una opción para el desarrollo local. RevIISE: Revista de Ciencias Sociales y Humanas, 6(6), 9-18. http://www.ojs.unsj.edu.ar/index.php/reviise/article/view/53

Observatorio de la Sostenibilidad en España [OSE]. (2009). Patrimonio Natural, Cultural y Paisajístico. Claves para la sostenibilidad territorial. OSE. http://www.upv.es/contenidos/CAMUNISO/info/ U0556177.pdf

Organización Mundial de Turismo [OMT]. (2012). Acerca de la OMT. https://www.unwto.org/es/acerca-de-la-organizacion-mundial-turismo

Osorio-García, M. (2006). La planificación turística. Enfoques y modelos. Quivera Revista De Estudios Territoriales, 8(1), 291-314. https://quivera.uaemex.mx/article/view/10574

Panez-Pinto, A., Faúndez-Vergara, R., \& Mansilla-Quiñones, C. (2017). Politización de la crisis hídrica en Chile: Análisis del conflicto por el agua en la provincia de Petorca. Agua y Territorio, 10, 131-148. https:// doi.org/10.17561/at.10.3614

Pastore, R. E. (2010). Un panorama del resurgimiento de la economía social y solidaria en la Argentina. Revista de Ciencias Sociales, 2(18), 47-74. http://ridaa.unq.edu.ar/handle/20.500.11807/1497

Porter, M. (1991). Ventaja competitiva. Creación y sostenimiento de un desempeño superior. Editorial Diana.

Ritchie, J. R. B., \& Crouch, G. I. (2003). The competitive destination: a sustainability perspective. CABI. https://doi.org/10.1079/9780851996646.0000

Subsecretaría de Turismo. (2018). Informe de intensidad turística y definición de destinos turísticos. http:// www.subturismo.gob.cl/wp-content/uploads/2015/09/Informe-de-Intensidad-Tur\%C3\%ADstica-y-Definici\%C3\%B3n-de-Destinos-Tur\%C3\%ADsticos-2018-1.pdf

Trigueros Boto, C. (2016). La arqueología como factor de desarrollo del turismo local. International Journal of Scientific Managment Tourism, 2(3), 355-368. http://www.ijosmt.com/index.php/ijosmt/article/view/144

UNESCO (1999). Convención sobre la protección del Patrimonio mundial, cultural y natural. UNESCO. https://whc.unesco.org/archive/convention-es.pdf

Vázquez Barquero, A. (2007). Desarrollo endógeno. Teorías y políticas de desarrollo territorial. Investigaciones Regionales - Journal of Regional Research, 11, 183-210. https:/investigacionesregionales.org/es/ article/desarrollo-endogeno-teorias-y-politicas-de-desarrollo-territorial/

Velasco Salinas, L. (2020). La valoración social del patrimonio cultural. Controversias y Concurrencias Latinoamericanas, 12(21), 305-322. https://ojs.sociologia-alas.org/index.php/CyC/article/view/217

Velázquez C., F. E. (2001). Desarrollo local y globalización. Una reflexión sobre América Latina. Revista Sociedad y Economía, 1, 9-25. https://sociedadyeconomia.univalle.edu.co/index.php/sociedad_y_economia/\%20article\%20/view\%20/4049

Zizumbo Villarreal, L. (2013). Las paradojas del desarrollo local y del turismo. Editorial Miguel Ángel Porrúa. 